\title{
Sorting out coronary stents, as time goes by
}

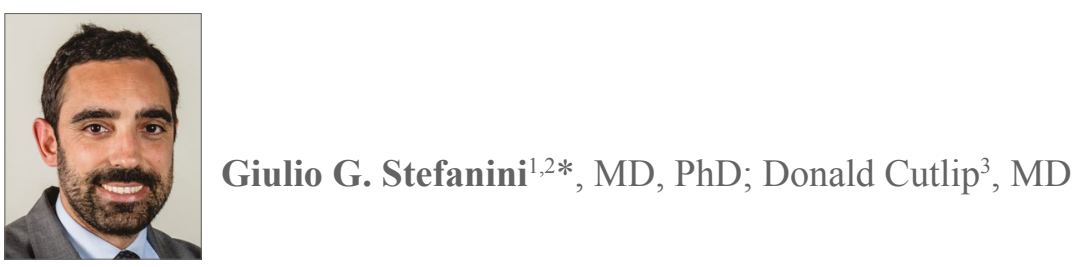

1. Department of Biomedical Sciences, Humanitas University, Pieve Emanuele - Milan, Italy; 2. Cardio Center, Humanitas Research Hospital, Rozzano - Milan, Milan, Italy; 3. The Cardiovascular Institute, Beth Israel Deaconess Medical Center, Harvard Medical School, Boston, MA, USA

"The fundamental things apply, as time goes by"

Herman Hupfeld (1894-1951)

Since their advent in clinical practice in 2002, drug-eluting stents (DES) have remarkably improved clinical outcomes of patients undergoing percutaneous coronary intervention (PCI), primarily by almost eliminating the risk of restenosis as compared to bare metal stents ${ }^{1}$. The treatment effect of early-generation DES, however, came at the expense of delayed arterial healing within the treated vessel, with a subsequently increased risk of stent thrombosis (ST) occurring after the cessation of dual antiplatelet therapy - namely very late $\mathrm{ST}^{2}$. Device iterations have been implemented in order to address this limitation by improving biocompatibility $^{3}$. Biodegradable polymer-based DES were developed based on evidence of local inflammation within the arterial wall related to persistence of durable polymer coatings during long-term follow-up in patients experiencing ST. The Nobori ${ }^{\circledR}$ biolimus-eluting stent (BES; Terumo, Tokyo, Japan) was one of the first biodegradable polymer-based DES introduced into clinical practice in Europe.

In this issue of EuroIntervention, Jakobsen and co-authors report the final five-year follow-up of the SORT-OUT V trial ${ }^{4}$, in which all-comer patients undergoing PCI were randomly allocated to the Nobori BES or the CYPHER ${ }^{\circledR}$ sirolimus-eluting stent
(SES; Cordis, Cardinal Health, Milpitas, CA, USA) - the efficacy gold standard among early-generation DES.

\section{Article, see page 1337}

The trial is part of the SORT-OUT trial series, which is based on data acquired through Danish national registries. The primary findings of SORT-OUT V, reported in 2013, failed to show the hypothesis of non-inferiority of Nobori BES as compared to CYPHER SES in terms of the composite endpoint of cardiac death, myocardial infarction (MI), target vessel revascularisation, and definite ST at nine months $(4.1 \%$ vs. $3.1 \%$, p for non-inferiority $=0.06)^{5}$. Since the benefits of biodegradable polymer coatings are expected to emerge during the long term, the authors extended the follow-up to five years, showing comparable outcomes with Nobori BES and CYPHER SES in terms of the composite primary endpoint (14.8\% vs. $15.8 \%$; OR 0.93, 95\% CI: 0.75-1.16; $\mathrm{p}=0.53$ ). Of note, this was the result of higher rates of the primary endpoint with the Nobori BES during the first year, compensated by lower rates beyond the first year up to five-year follow-up. Similar timedependent changes in treatment effects were observed in other allcomer DES trials using the CYPHER SES as comparator, such as the SORT-OUT III ${ }^{6}$, PROTECT ${ }^{7}$, and LEADERS ${ }^{8}$ trials. 
Jakobsen and co-authors should be congratulated for reporting the long-term follow-up of this important registry-based trial. Randomised trials based on national registries are cost-effective, pragmatic, and therefore of great value for the evaluation of medical devices. Notwithstanding this, registry-based randomised trials are subject to intrinsic potential inaccuracies related to discharge coding $^{9,10}$ that may introduce a source of ascertainment bias. Specifically, adverse events with complex definitions (such as MI) or rare adverse events (such as ST) require an active screening and review of potential events by an independent clinical events committee for an adequate adjudication process. Conversely, the value of registry-based trials is undisputed for the evaluation of treatment effects on hard clinical endpoints of simple detection and definition such as all-cause mortality ${ }^{11}$. This is evident from the comparison of event rates between all-comer trials based on registries and those based on dedicated databases with active follow-up (Table 1). While rates of events easy to detect and adjudicate such as all-cause mortality are consistent across different trials, rates of MI appear to be affected by the study design.

The immediate clinical implications of the long-term findings of SORT-OUT V are limited, since the investigated DES are outdated. The manufacturing of the CYPHER SES was discontinued in 2011 and the Nobori BES has largely been replaced by newer biodegradable polymer-based DES. This reflects the rapid innovation in the field of coronary stents.

The observation of relative changes in device safety and efficacy over time, however, should influence the design of future studies investigating novel coronary devices such as fully bioresorbable scaffolds. It is noteworthy that contemporary newgeneration DES have reduced the risk of ST to at least the level of bare metal stents, while maintaining or improving device effectiveness compared with early-generation $\mathrm{DES}^{12}$. In view of the
Table 1. One-year event rates in recent all-comer trials on drug-eluting stent comparisons.

\begin{tabular}{|l|c|c|c|c|}
\multicolumn{1}{|c|}{ Trial } & Year & Comparison & $\begin{array}{c}\text { All-cause } \\
\text { mortality }\end{array}$ & $\begin{array}{c}\text { Myocardial } \\
\text { infarction }\end{array}$ \\
\hline SORT-OUT III & 2010 & Endeavor ZES vs. CYPHER SES & $2.4 \%$ & $1.2 \%$ \\
\hline SORT-OUT IV & 2012 & XIENCE EES vs. CYPHER SES & $2.7 \%$ & $1.3 \%$ \\
\hline SORT-OUT V & 2013 & Nobori BES vs. CYPHER SES & $2.3 \%$ & $1.2 \%$ \\
\hline SORT-OUT VI & 2014 & Resolute ZES vs. BioMatrix BES & $3.0 \%$ & $2.0 \%$ \\
\hline SORT-OUT VII & 2016 & Orsiro SES vs. Nobori BES & $2.6 \%$ & $2.0 \%$ \\
\hline COMPARE & 2010 & XIENCE EES vs. TAXUS PES & $2.0 \%$ & $4.0 \%$ \\
\hline RESOLUTE-AC & 2010 & Resolute ZES vs. XIENCE EES & $2.1 \%$ & $4.1 \%$ \\
\hline TWENTE & 2011 & Resolute ZES vs. XIENCE EES & $2.1 \%$ & $4.6 \%$ \\
\hline COMPARE-II & 2013 & Nobori BES vs. XIENCE EES & $1.4 \%$ & $2.7 \%$ \\
\hline DUTCH-PEERS & 2013 & Resolute ZES vs. PROMUS EES & $2.0 \%$ & $2.0 \%$ \\
\hline BIOSCIENCE & 2014 & Orsiro SES vs. XIENCE EES & $2.9 \%$ & $4.1 \%$ \\
\hline
\end{tabular}

low stent-related event rates occurring during the late follow-up phase with the use of contemporary DES, it appears unlikely that these may determine time-dependent changes in treatment effects as observed in SORT-OUT V.

Overall, the SORT-OUT V five-year findings highlight once again the need for a long-term evaluation of novel coronary devices in populations representative of routine clinical practice for a complete characterisation of their efficacy and safety profile. In this regard, a Task Force of the European Society of Cardiology (ESC)/European Association for Percutaneous Cardiovascular Interventions (EAPCI) has recently provided recommendations for a new regulatory process for coronary stents in Europe (Figure 1) ${ }^{1}$. While pointing out that the life cycle of coronary stents is short due to rapid device iteration and innovation - which can make devices clinically obsolete within five years - the Task Force

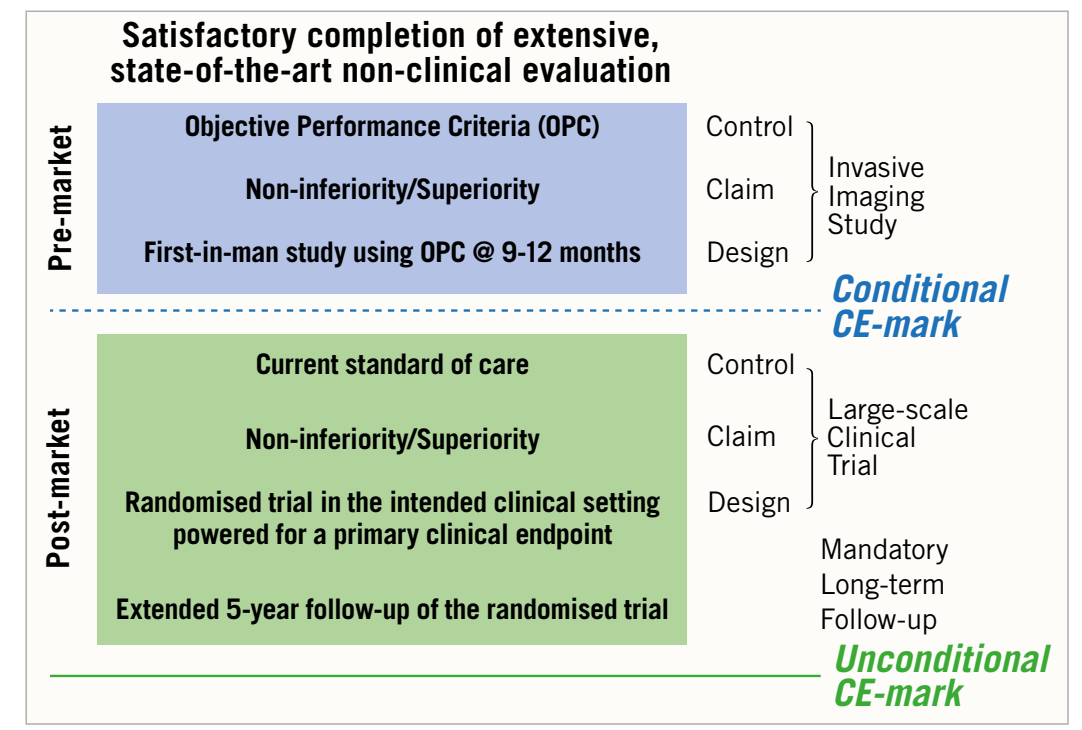

Figure 1. Clinical development plan proposed by the ESC/EAPCI Task Force on coronary stent evaluation. Adapted from Byrne et al. Eur Heart J. $2015^{1}$ with permission. 
acknowledged the critical role of long-term post-marketing surveillance in the clinical evaluation process of coronary devices. For this purpose, a close collaboration among device manufacturers, clinical investigators, physicians, and regulatory authorities is pivotal. However, the need for long-term follow-up should not delay but rather condition novel coronary device approval, since innovation remains the basis of therapeutic advances, and a timely access for patients to improved devices is warranted.

\section{Conflict of interest statement}

G. Stefanini has received a research grant (to the institution) from Boston Scientific, and speaker/consulting fees from B. Braun, Biosensors, Boston Scientific, and Edwards Lifesciences. D. Cutlip has received research funding paid to the institution from Medtronic, Boston Scientific, and CeloNova BioSciences.

\section{References}

1. Byrne RA, Serruys PW, Baumbach A, Escaned J, Fajadet J, James S, Joner M, Oktay S, Jüni P, Kastrati A, Sianos G, Stefanini GG, Wijns W, Windecker S. Report of a European Society of Cardiology-European Association of Percutaneous Cardiovascular Interventions task force on the evaluation of coronary stents in Europe: executive summary. Eur Heart J. 2015;36:2608-20.

2. Raber L, Magro M, Stefanini GG, Kalesan B, van Domburg RT, Onuma Y, Wenaweser P, Daemen J, Meier B, Juni P, Serruys PW, Windecker S. Very late coronary stent thrombosis of a newer-generation everolimus-eluting stent compared with earlygeneration drug-eluting stents: a prospective cohort study. Circulation. 2012;125:1110-21.

3. Stefanini GG, Taniwaki M, Windecker S. Coronary stents: novel developments. Heart. 2014;100:1051-61.

4. Jakobsen L, Christiansen EH, Maeng M, Hansen KN, Kristensen SD, Bøtker HE, Terkelsen CJ, Jensen SE, Raungaard B, Madsen M, Lassen JF, Jensen LO; SORT OUT (Scandinavian Organization for Randomized Trials with Clinical Outcome) V investigators. Final five-year outcomes after implantation of biodegradable polymer-coated biolimus-eluting stents versus durable polymer-coated sirolimus-eluting stents. EuroIntervention. 2017;13:1337-45.

5. Christiansen EH, Jensen LO, Thayssen P, Tilsted HH, Krusell LR, Hansen KN, Kaltoft A, Maeng M, Kristensen SD, Botker HE, Terkelsen CJ, Villadsen AB, Ravkilde J, Aaroe J, Madsen M, Thuesen L, Lassen JF; Scandinavian Organization for Randomized Trials with Clinical Outcome (SORT OUT) V investigators. Biolimus-eluting biodegradable polymer-coated stent versus durable polymer-coated sirolimus-eluting stent in unselected patients receiving percutaneous coronary intervention (SORT OUT V): a randomised non-inferiority trial. Lancet. 2013;381:661-9.
6. Maeng M, Tilsted HH, Jensen LO, Krusell LR, Kaltoft A, Kelbaek H, Villadsen AB, Ravkilde J, Hansen KN, Christiansen EH, Aaroe J, Jensen JS, Kristensen SD, Botker HE, Thuesen L, Madsen M, Thayssen P, Sorensen HT, Lassen JF. Differential clinical outcomes after 1 year versus 5 years in a randomised comparison of zotarolimus-eluting and sirolimus-eluting coronary stents (the SORT OUT III study): a multicentre, open-label, randomised superiority trial. Lancet. 2014;383:2047-56.

7. Camenzind E, Wijns W, Mauri L, Kurowski V, Parikh K, Gao R, Bode C, Greenwood JP, Boersma E, Vranckx P, McFadden E, Serruys PW, O'Neil WW, Jorissen B, Van Leeuwen F, Steg PG; PROTECT Steering Committee and Investigators. Stent thrombosis and major clinical events at 3 years after zotarolimus-eluting or sirolimus-eluting coronary stent implantation: a randomised, multicentre, open-label, controlled trial. Lancet. 2012;380:1396-405.

8. Serruys PW, Farooq V, Kalesan B, de Vries T, Buszman P, Linke A, Ischinger T, Klauss V, Eberli F, Wijns W, Morice MC, Di Mario C, Corti R, Antoni D, Sohn HY, Eerdmans P, RademakerHavinga T, van Es GA, Meier B, Jüni P, Windecker S. Improved safety and reduction in stent thrombosis associated with biodegradable polymer-based biolimus-eluting stents versus durable polymer-based sirolimus-eluting stents in patients with coronary artery disease: final 5-year report of the LEADERS (Limus Eluted From A Durable Versus ERodable Stent Coating) randomized, noninferiority trial. JACC Cardiovasc Interv. 2013;6:777-89.

9. Westaby S, Archer N, Manning N, Adwani S, Grebenik C, Ormerod O, Pillai R, Wilson N. Comparison of hospital episode statistics and central cardiac audit database in public reporting of congenital heart surgery mortality. BMJ. 2007;335:759.

10. Patrick H, Sims A, Burn J, Bousfield D, Colechin E, Reay C, Alderson N, Goode S, Cunningham D, Campbell B. Monitoring the use and outcomes of new devices and procedures: how does coding affect what Hospital Episode Statistics contribute? Lessons from 12 emerging procedures 2006-10. J Public Health (Oxf). 2013;35: 132-8.

11. Frobert O, Lagerqvist B, Olivecrona GK, Omerovic E, Gudnason T, Maeng M, Aasa M, Angeras O, Calais F, Danielewicz M, Erlinge D, Hellsten L, Jensen U, Johansson AC, Karegren A, Nilsson J, Robertson L, Sandhall L, Sjogren I, Ostlund O, Harnek J, James SK; TASTE Trial. Thrombus aspiration during ST-segment elevation myocardial infarction. $N$ Engl J Med. 2013;369:1587-97.

12. Palmerini T, Benedetto U, Biondi-Zoccai G, Della Riva D, Bacchi-Reggiani L, Smits PC, Vlachojannis GJ, Jensen LO, Christiansen EH, Berencsi K, Valgimigli M, Orlandi C, Petrou M, Rapezzi C, Stone GW. Long-Term Safety of Drug-Eluting and Bare-Metal Stents: Evidence From a Comprehensive Network Meta-Analysis. J Am Coll Cardiol. 2015;65:2496-507. 